\title{
Effects of prey size on poststrike behavior in rattlesnakes (Crotalus durissus, C. enyo, and C. viridis).
}

\author{
CHARLES W. RADCLIFFE, DAVID CHISZAR, and BARBARA O'CONNELL \\ Denver Zoological Gardens and University of Colorado, Boulder, Colorado 80309
}

\begin{abstract}
Rattlesnakes of three taxa (Crotalus durissus, $C$. enyo, and C. viridis) struck and released large rodent prey but held smaller rodents in their jaws after striking. The specimens of $C$. enyo were clearest in this regard; almost all large prey were released, and all small prey were held. This finding is consistent with the fact that large rodents are more dangerous to rattlesnakes than are small rodents. Accordingly, it appears that rattlesnakes have evolved differential predatory strategies for dealing with prey of varying size. Speculation is offered about the manner in which these respective strategies are activated or selected during predatory episodes.
\end{abstract}

Rattlesnakes typically strike and release rodent prey, permitting the envenomated rodent to wander up to several meters from the site of attack prior to succumbing to the venom. Within 5 min after a successful strike, the snake begins to emit a high rate of tongue flicks (Chiszar, Radcliffe, \& Scudder, 1977; Chiszar, Radcliffe, \& Smith, 1978; see Chiszar \& Scudder, 1980, for a review) and becomes extremely sensitive to chemical cues arising from the envenomated prey (Chiszar, Duvall, Scudder, \& Radcliffe, 1980; Duvall, Chiszar, Trupiano, \& Radcliffe, 1978; Duvall, Scudder, \& Chiszar, 1980). Indeed, a rattlesnake that has struck a rodent can follow the latter's trail with exactitude (Burghardt, 1970; Dullemeijer, 1961; Golan, Radcliffe, Miller, \& Chiszar, Note 1).

That rattlesnakes generally release rodent prey after striking is probably an adaptation that protects the snakes from rodent teeth and claws. Although the snake risks losing the rodent by releasing it, the obviation of tissue damage that could otherwise occur probably compensates the predator for any fitness reduction deriving from this strategy. Moreover, the snake's ability to trail an envenomated rodent minimizes the probability of losing the prey and, therefore, minimizes the disadvantages of releasing prey after the strike.

Adult rodents are far more dangerous to rattlesnakes than smaller, young rodents. Tooth size, claw size, and defensive ability in rodents are all positively correlated with age and body weight. If snakes release adult rodents because of the dangers involved in holding them in the jaws while venom takes effect $(10-300 \mathrm{sec})$, then very young and relatively defenseless rodents might not be

The authors thank the M. M. Schmidt Foundation for financial support. H.P. Alpern and the Institute for Behavioral Genetics kindly provided mice for these experiments. Reprint requests should be sent to $D$. Chiszar, Department of Psychology, University of Colorado, Boulder, Colorado 80309. released. Indeed, neonatal rodents are not dangerous at all, and some rattlesnakes do not even bother to envenomate them before swallowing. The present study was designed to measure the probabilities of holding vs. releasing by rattlesnakes after striking postweanling rodents of various sizes.

\section{METHOD}

\section{Subjects and Maintenance Conditions}

Nineteen rattlesnakes were observed in this experiment (eight Crotalus enyo, five $C$. viridis, and six $C$. durissus). All snakes were housed individually in glass terraria $(50 \times 27.5 \times$ $30 \mathrm{~cm}$ ) containing paper floor coverings and glass vessels filled with water. Temperature was kept at $26^{\circ} \mathrm{C} \pm 1^{\circ} \mathrm{C}$ by electric heaters during photophase $(0700-1900)$ and at $23^{\circ} \mathrm{C} \pm 1{ }^{\circ} \mathrm{C}$ during scotophase. All snakes were between 3 and 4 years old and had been in captivity for the last 2 years, during which they had been accepting mouse (Mus musculus) prey on a biweekly schedule. The specimens of $C$. durissus were occasionally offered rats (Rattus norvegicus, Sprague-Dawley derived), and these prey were readily accepted.

\section{Procedure}

On a regularly scheduled feeding day, specimens of $C$. enyo and $C$. viridis were offered either a small $(\leqslant 15 \mathrm{~g})$ or a large ( $>15 \mathrm{~g}$ ) mouse (Mus musculus). Each snake was observed twice, once with a small mouse and once with a large one. Half the snakes received the small mouse first and the large one next ( 2 weeks later); the remaining snakes received the reverse order. Snakes always struck immediately, and we observed whether the prey was released or held in the jaws following the strike.

Specimens of $C$. durissus were treated similarly, except that prey were Sprague-Dawley-derived rats (small $\leqslant 30 \mathrm{~g}$; large $>30 \mathrm{~g}$ ).

In all cases, the rodent was suspended by its tail, which was held with long forceps. The rodent was then lowered into the snake's cage and slowly brought within striking range. The tail was released from the forceps immediately after the strike. "Hold" was recorded if the snake maintained a grip on the mouse for at least $10 \mathrm{sec}$ after striking; otherwise, "release" was recorded. In almost all cases, a "hold" actually involved maintaining a grip on the mouse from the strike until swallowing was complete. 


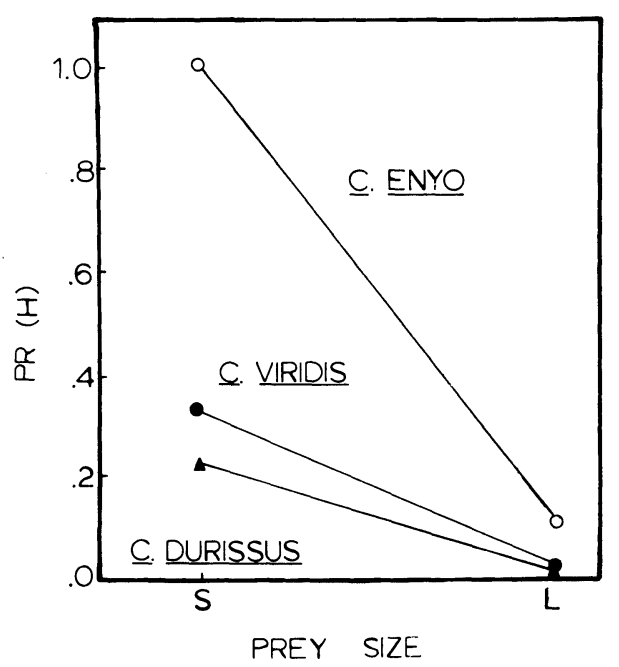

Figure 1. Probability of holding (H) prey in the jaws after striking small (S) and large (L) rodent prey by three taxa of rattlesnakes.

\section{RESULTS}

The probability of holding $(\mathrm{H})$ after strike is plotted in Figure 1 as a function of prey size for each species of rattlesnake. It is clear that $\mathrm{H}$ occurred more frequently after snakes struck small rodents than after they struck large ones $\left[\chi^{2}(1)=10.36, p<.01\right.$; also, $p<.01$, by sign test]. In fact, only one snake (a $C$. enyo) exhibited $\mathrm{H}$ after striking a large rodent, whereas 10 did so after striking small rodents. Interestingly, the species differed in that all $C$. enyo held onto small prey, whereas this behavior was seen in only two $C$. viridis and one $C$. durissus. The last two species did not differ from each other $\left(\chi^{2}<1\right)$, but together they differed from the $C$. enyo $\left[\chi^{2}(1)=9.16, \mathrm{p}<.01\right]$.

\section{DISCUSSION}

These data indicate that prey size and/or its correlates (e.g., strength, defensive ability) are determinants of poststrike behavior in rattlesnakes. Gans (1966) speculated that rattlesnakes may be able to sense prey weight as a consequence of the biomechanics of striking. Immediately after the strike, the snake's head and neck are retracted. During this action, a small prey is easily lifted off the substrate, whereas a large one causes the snake's trunk to shift. Proprioception arising from these actions might participate in determining whether the prey is held or released. Our data are consistent with these ideas. Alternatively, it is possible that the decision to hold or release is made prior to striking, based on visual, thermal, or chemical cues arising from prey. One way to test this is to present models or actual prey that are equal in visual, thermal, and chemical characteristics but differ in mass. If snakes exhibit $\mathrm{H}$ in a massdependent manner, then the decision to hold or release must be made during or after the strike, rather than before it.

The present data may have an important ecological implication. If rattlesnakes rarely lose envenomated rodents after releasing them, then there would be no strong selective pressure to hold onto small ones. They could just as well be treated like adult rodents. On the other hand, if released prey are frequently lost (Gillingham \& Baker, in press) or if small prey are especially likely to be lost, then predator fitness would be enhanced by holding onto small and nondangerous prey items, and selection would be expected to favor appropriate decision making systems. The results reported here suggest that such selection pressures have occurred in the natural history of rattlesnakes. Furthermore, these selective pressures may have been more intense for $C$. enyo than for $C$. viridis and $C$. durissus, thereby accounting for the species differences observed in this study.

\section{REFERENCE NOTE}

1. Golan, L., Radcliff, C. W., Miller, T., \& Chiszar, D. Prey trailing by the prairie rattlesnake (Crotalus v. viridis). Manuscript in preparation, 1980.

\section{REFERENCES}

Burghardt, G. M. Chemical perception in reptiles. In J. W. Johnston, D. G. Moulton, \& A. Turk (Eds.), Communication by chemical signals. New York: Appleton-Century-Crofts, 1970.

Chiszar, D., Duvall, D., Scudder, K., \& Radcliffe, C. W. Simultaneous and successive discriminations between envenomated and nonenvenomated mice by rattlesnakes (Crotalus durissus and C. viridis). Behavioral and Neural Biology, 1980, 29, 518-521.

Chiszar, D., Radcliffe, C. W., \& Scudder, K. M. Analysis of the behavioral sequence emitted by rattlesnakes during feeding episodes. I. Striking and chemosensory searching. Behavioral Biology, 1977, 21, 418-425.

Chiszar, D., Radcliffe, C. W., \& Smith, H. M. Chemosensory searching for wounded prey by rattlesnakes is released by striking: A replication report. Herpetological Review, 1978, 9, 54-56.

Chiszar, D., \& Scudder, K. M. Chemosensory searching by rattlesnakes during predatory episodes. In D. Muller-Schwarze \& R. M. Silverstein (Eds.), Chemical signals: Vertebrates and aquatic invertebrates. New York: Plenum, 1980.

DullemeiJer, P. Some remarks on the feeding behavior of rattlesnakes. Koninklijke Nederlandische Academie van Wetenschappen (Series C), 1961, 64, 383-396.

Duvall, D., Chiszar, D., Trupiano, J., \& Radcliffe, C. W. Preference for envenomated rodent prey by rattlesnakes. Bulletin of the Psychonomic Society, 1978, 11, 7-8.

Duvall, D., Scudder, K. M., \& Chiszar, D. Rattlesnake predatory behavior: Mediation of prey discrimination, and release of swallowing by odors associated with envenomated mice. Animal Behaviour, 1980, 28, 674-683.

GaNs, C. The biting behavior of solenoglyph snakes-Its bearing on the pattern of envenomation. Proceedings of the International Symposium on Venomous Animals. Sao Paulo, Brazil: Instituto Butantan, 1966.

Gillingham, J. C., \& BaKeR, R. R. Evidence for scavenging behavior in the western diamondback rattlesnake (Crotalus atrox). Zeitschrift für tierpsychologie, in press.

(Received for publication November 24, 1980.) 